\title{
Effect of Heat Treatment and Bake Hardening on the Mechanical Properties and Microstructure of Dual Phase Steel
}

\author{
Abbas Abdul Hussein Abid ${ }^{1} \&$ Abbas Fadhil Abbas ${ }^{2}$ \\ ${ }^{1}$ Department of Mechanical Engineering, College of Engineering, Baghdad University, Baghdad, Iraq. ${ }^{2}$ M.sc general \\ directorate of vocational education, Iraq. \\ *corresponding author: email address: abbasaltaee@yahoo.com ${ }^{\mathbf{1}}$, fadel.metalabbas@yahoo.com²
}

\begin{abstract}
Abstruct
This research is concerned with study of the effect heat treatment and the bake hardening process on dual phase steels which can be obtain by intercritical annealing process. Hardness, microstructure and tensile specimens were prepared according to standards. Used specimens was with different carbon content $(0.12,0.096$ and 0.064$)$. The normalizing heat treatment was conducted on low carbon steel, to remove the effect of the previous manufacturing processes. Intercritical annealing was used as a heat treatment to obtain the dual phase steel, the carbon steel was quenched from $760{ }^{\circ} \mathrm{C}$ this temperature lies between the critical points. It has been found that after intercritical annealing process has transformation accrue from pearlite structure resulting from the normalization process to a new structure contain ferrite and martensite. The hardness of dual-phase steel obtained by intercritical annealing is higher than of the steel that was normalized as well as the carbon content of the steel affects the hardness. Tensile test results showed that the ultimate tensile strength and yield strength increased after intercritical annealing process compared to other specimens were normalized, content of carbon also effect on the ultimate tensile strength and yield point. The dual phase steel is characterized with no visible yield point due to the dislocations movement are restricted. Dual phase steel yield point re-appear after pre-strained at 3, 5, 8, $10 \%$, and baked to $170{ }^{\circ} \mathrm{C}$. The ultimate tensile strength and the yield point for the pre-strained and baked specimens were higher than the other tensile specimens which conducted with normalizing or intercritical annealing only due to the diffused carbon atoms that pin dislocations and prevent it is movement. Baking process is affected by several factors such as carbon ratio and the amount of prestrain. It is found that when carbon content increase, the number of diffused carbon atoms will increase. Amount of pre-strain effect on the mechanical properties after baking process, where it was found that when the mount of pre-strain increase the ultimate tensile strength and yield point stress will increase.
\end{abstract}

Keywords intercritical annealing, dual phase steel, tensile properties, hardness.

Paper history: (Recived:23/2/2017; Accepted:25/2/2018)

\section{Introduction}

The demand of environment-friendly vehicles that have better fuel economy and lower $\mathrm{CO} 2$ emissions compels automakers to apply advanced technology and new materials in vehicle manufacturing [1]. Automotive materials must have a combination of high strength, good ductility, reasonable yield strength and interest originates from the demand for lighter more fuel efficient vehicles[2]. Dual-phase sheet steels find widespread use in the automotive sector for structural applications. Their high strength-to-weight ratio, low yield-to-ultimate strength ratio combined with a high initial work hardening rate and good formability make them particularly suited for these applications ${ }^{3}$ weight reduction, cost lowering and safety improvement of vehicles precipitate for the evolution of new high strength steels with a combination of improved strength and formability. Mild steel and traditional high strength steel grades have been the generality used materials for automotive body-in-white (BIW) synthesis. The weight provision prospect for BIW applications presented by materials like aluminum and magnesium alloys, as well as composite materials, has prompted the steel making to incubate a new grades of steel, known as advanced high strength steels (AHSS). The strength of AHSS permit, for lighter BIW structures meanwhile down-gauging, without affecting crashworthiness or material stiffness contrast with conventional steels. Due to these features, AHSSs are the fastest rising light weighting material in vehicle structures. Dual Phase (DP) steels are a class of advanced high strength steels (AHSS) characterized by a microstructure consisting of a mixture of hard martensite and softer ferrite which combines high strength with good ductility. Their excellent properties have made them the most widely used of all AHSS in the automotive sector; however, certain aspects of DP steel behavior, notably the formability, limit the range of accessible parts[4].Additionally, DP steels, the volume fractions of both phases are the most critical parameter in determining the final mechanical properties[5]. Dual-phase steels consist of martensite islands embedded in a ferrite matrix. Typically, the martensite volume fraction is around 15$25 \%{ }^{6}$. Production of dual phase microstructure requires the water quenching after the annealing at intercritical region which is between A1 and A3 temperatures. Initial microstructures (before annealing) can be martensite, ferrite + pearlite or austenite and affect the final 
morphologies and properties. Initial microstructure is annealed at an intercritical region named different production methods which are respectively, intermediate quenching, intercritical annealing and step quenching. Amount of the different phases in dual phase microstructure and their morphologies are key parameters for controlling the mechanical properties. Increasing the annealing temperature provides more martensite volume fractions so the controlling the phase distributions is possible with controlling the annealing temperature[7]. Ferrite martensite dual phase (DP) steels have microstructure include hard martensite islands entrenched in a soft and ductile ferrite matrix. These favorable properties are definitely related to typical microstructure of dual phase steels in which, soft ferritic network provides good ductility; while, hard particles and martensite phase play the load bearing role. This microstructure, in fact, shows some kind of metallic composite. Beside these features, properties such as continuous yielding behavior, uniform plastic deformation and high elongation (good formability) are important features of dual phase steels [8].The distribution of martensite also affects the mechanical behavior. Martensite regions existing as isolated areas within ferrite matrix result in a better combination of strength and ductility than martensite regions forming a chain-like network structure surrounding ferrite ${ }^{9}$. Furthermore the dual-phase steels often show a large potential for bake hardening $(\mathrm{BH}) . \mathrm{BH}$ refers to the increase in yield strength that occurs as a result of the paint baking treatment of the formed auto-body parts. The primary mechanism that causes the additional strengthening is the immobilization of dislocations[10] .The bake hardening treatment has been extensively used for the automotive steel sheets to enhance the yield strength after prestrainingbecause many auto components undergo a small amount of straining during the final forming operation before the baking process ${ }^{11}$. There are many factors effect on bake hardening such as baking temperature and time, amount of pre-strain, amount of solute carbon. These parameters may have an effect on the dislocation density, increasing the amount of solute carbon in steel, BH response should also increase this is because of the fact that with increasing solute carbon in steel, more solute is available to pin mobile dislocations and the formation of clusters will occur more rapidly. The application of prestrain to the specimens increases the dislocation density. Additional dislocations generated during prestraining are pinned by free solute atoms that diffuse to the dislocation core during baking and as a result YS increases[12].The bake hardening response of $\mathrm{BH}$ grade steel is a function of both time and temperature and prestrain level. The automobile industries maintain a standard schedule for the bake hardening process during the paint baking cycle. In a temperature range, where recovery of the cold worked structure is negligible, the Strength increases at a constant temperature asymptotically with time and at a constant time, exponentially with temperature[13].many previous researches concerning dual phase steel, and bake hardening has been made K.A. Bello etc2007studied, impact toughness tests were conducted on dual phase steel specimens[14]. S. K. AKAYetc2009 studied the effect of heat treatment on the microstructure, crystal structure and electric resistivity of dual phase steel[15].M. R. AKBARPOUR etc2010 study the effect of The holding time is an important parameter in the intercritical annealing at constant temperature and influencing mechanical properties of this steel[16].Martin Gaško1 etc2011they studied the correlation between hardness and ultimate tensile strength of steel sheets in the experiments were performed on dual phase steels[17]. L. Durrenbergera etc2011 the researchers studied the effects of pre-strain on the crushing properties of a crash-box structure of (Dual-Phase DP600)[18] .Emil EVIN 2013presented the basic concepts of advanced high strength dual phase steels for automotive applications, including the design of chemical composition, microstructure and mechanical properties[19].

\section{Exprimental Work}

\section{Materials}

The steel grades used in this research work were selected from standard types of carbon steel (ASTM designation A 328/ A 328 M steel sheet piling) with different carbon content but all of these grades are belong to low carbon steel, specifically to dead mild steel. The difference in carbon content will help us to understand the effect of heat treatments, pre-strain and bake hardening on the microstructure and mechanical properties of dualphase steel. The chemical compositions of steel grades are shown in Table1. Chemical analysis of the steels was carried out by (thermo ARL 3460 in Specialized General Company for Examination and Rehabilitation engineering (S.I.E.R)).

Table 1 the chemical composition of the investigated steel

\begin{tabular}{llllllll}
\hline $\mathrm{C}$ & $\mathrm{Si}$ & $\mathrm{Mn}$ & $\mathrm{P}$ & $\mathrm{S}$ & $\mathrm{Cr}$ & $\mathrm{Mo}$ & $\mathrm{Ni}$ \\
\hline 0.12 & 0.005 & 0.48 & 0.008 & 0.009 & 0.008 & 0.002 & 0.035 \\
0.096 & 0.015 & 0.364 & 0.014 & 0.028 & 0.015 & 0.002 & 0.026 \\
& & & & & & & \\
0.061 & 0.012 & 0.334 & 0.007 & 0.010 & 0.022 & 0.002 & 0.030 \\
\hline
\end{tabular}




\section{Heat Treatment}

Heat treatment was performed using a Sola basic LINDBERG type Muffle furnace with temperature controller to 1200 degrees $^{\circ} \mathrm{C}$, with accuracy ranging between $\left(\mathbf{( 5}^{\circ} \mathbf{C}\right)$. Normalizing was first done on each sample within a temperature $910{ }^{\circ} \mathrm{C}$ for 10 minutes the temperature and time were chosen to ensure austenitization had been complete before, intercritical annealing was carried out. Normalized samples were air cooled down to room temperature before quenching (Intercritical annealing), the purpose of the treatment is to remove or eliminate the effects of any previous coldworking which occurs because of previous manufacturing processes. After doing normalizing process the intercritical annealing carried out at $\left(760^{\circ} \mathrm{C}\right)$, and the holding time was $(10 \mathrm{~min})$, followed by quenching in Brine solution $(10 \% \mathrm{NaCl})$ to obtain dual Phase steel and to create martensite structure. The selected value of temperature because Intercritical annealing process is a heat treatment in which steel is heated to temperature between upper critical temperature (A3) and lower critical temperature (A1) onFe-C phase diagram. A detail of the heat treatment regime used for the present work presented is presented in Table 2

Table 2 the heat treatments methods used for all specimes

\begin{tabular}{llll}
\hline Heat treatment & Temperature $\left({ }^{\circ} \mathbf{C}\right)$ & $\begin{array}{l}\text { Holding } \\
\text { time (min) }\end{array}$ & $\begin{array}{l}\text { Cooling } \\
\text { medium }\end{array}$ \\
\hline normalizing & 900 & 10 & Air \\
$\begin{array}{l}\text { Inter-critical } \\
\begin{array}{l}\text { annealing } \\
\text { (quenching) }\end{array}\end{array}$ & 760 & 10 & $\begin{array}{l}\text { Brine }(10 \% \\
\text { NaCl water })\end{array}$ \\
\hline
\end{tabular}

\section{Pre-strain process}

Most of the auto body parts experience a little measure of pre- straining throughout the last framing operation before the baking process, so that groups of dual phase steel specimens which are specially prepared for tensile testing, carried out by subjecting the samples to a small amount of prestrain at room temperature. Tensile specimens were machined from the strip and subjected to 3, 5, 8 and $10 \%$ prestraining in tensile testing machine type (Laryee tensile machine). A strain rate of $5 \mathrm{~mm} / \mathrm{min}$ was employed for all

tested specimens, the test machine has a maximum capacity of $(100 \mathrm{KN})$ before bake hardened. The application of pre-strain level to the specimens will effect on dislocation density.

\section{Baking process}

After the completion of pre-strain process on the samples, they subjected to baking, this process made by heating a group of tensile specimens (with or without pre-strain ) to a temperature of $\left(170^{\circ} \mathrm{C}\right)$ for 20 minutes The samples were baked accordance with SAE J2340 (Society of Automotive Engineers)Standards.

\section{Mechanical properties tests}

\section{Tensile testing}

The tensile tests were performed using tensile testing machine type (Laryee tensile machine). A strain rate of 5 $\mathrm{mm} / \mathrm{min}$ was employed for all tested specimens, the test machine has a

maximum capacity of $(100 \mathrm{KN})$ with a speed5 $\mathrm{mm} / \mathrm{min}$ was employed for all tested specimens. The specimen for tensile test has been prepared according to ASTM E-8 standard for thin specimens, the schematic shape and dimension of specimen is shown in figure 1.The tensile testing of the samples was conducted at the strength of materials Laboratory at the Mechanical Engineering Department, University of Baghdad.

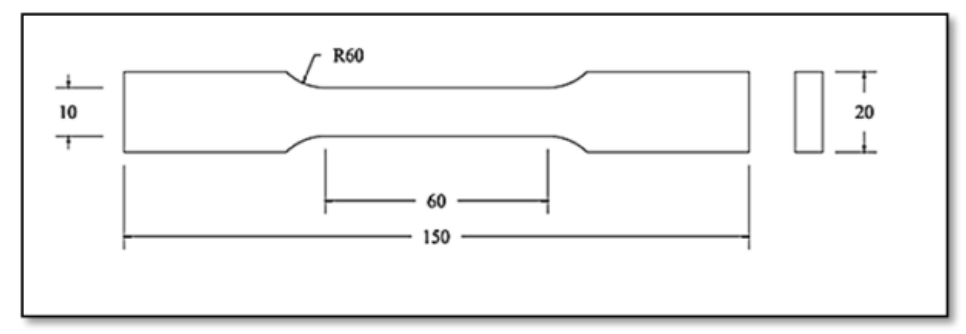

Figure 1: the shape and dimension specimen of tensile test 


\section{Microhardness Testing}

Vickers Microhardness test was used to measure the hardness of all specimens because it is most suitable for thin specimens and a load of (300 g) was employed. The mean of at least three tests were used. Cold setting resin was used to mount the specimens through the work to avoid any changes in the specimens that may occur in hot press mounting. These mounted specimens were polished and etched in Nital (3\% $\underline{\mathrm{HNO}}_{3}$ in Alcohol), for hardness tests and microstructure imaging

\section{Result and Discussion}

\subsection{Tensile properties}

The results obtained from the tensile test were divided according to the process and the conditions that were conducted on the samples, the different conditions includes normalizing, intercritical annealing to produce dual phase steel, baking and baking with prestrain. The results obtained for tensile test of normalized specimens are presented in Figure (2) this figure showed yield point phenomenon or discontinuous yielding the reason for this behaviour is the presence of interstitial atoms like carbon and nitrogen as the alloying elements.

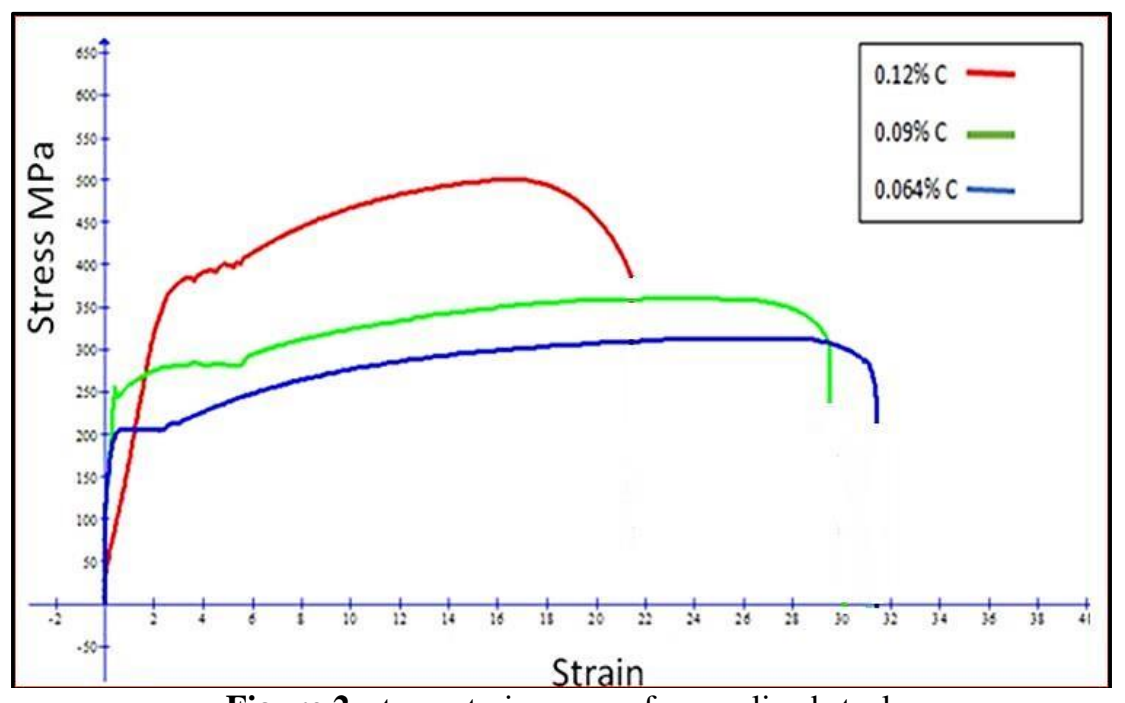

Figure 2: stress strain curve of normalized steel

The dislocations which are understood to be the cause of plastic deformation are pinned to these interstitial solutes and hence become immobile. Also with the initiation of the plastic deformation the number of dislocationsis increase due to the formation of Cottrell atmosphere. The dislocations movement are restricted and causes the yield point phenomenon, this phenomena usually seen in mild steel. The microstructures of air cooled steels consist of mixtures of ferrite and pearlite, since the structure of pearlite composed of alternating layers of ferrite and cementite that occurs during slow cooling pearlite forms by a eutectoid reaction. Relationship between mechanical properties and microstructural characteristics of pearliteit seems that yield strength, ultimate tensile strengthwas low if we compare it with steels obtained from another process such as intercritical annealing because transformed Austenite into Ferrite and pearlite in low cooling rate. The YS and UTS are both increases with the increase in carbon content. Figure (3) presented the tensile test result of dual phase steel that obtained from intercritical annealing process, in this process steel is heated to temperature between upper critical temperature (A3) and lowercritical temperature (A1) Martensite is formed in steels due to rapid cooling (quenching) from austenite region, thermal martensitic transformation begins when traps carbon atoms that do not have time to diffuse out of the crystal structure. Austenite is a solid solution of iron and alloying elements. As a result of the quenching, the face-centered cubic austenite transforms to a highly strained body-centered tetragonal martensite that is supersaturated with carbon. Austenite transformation to martensite is diffusion less shear -type transformation so that the shear deformations that result produce a large number of dislocations, which is a primary strengthening mechanism of steels. This is why Martensite has a higher strength than pearlite and Austenite. 


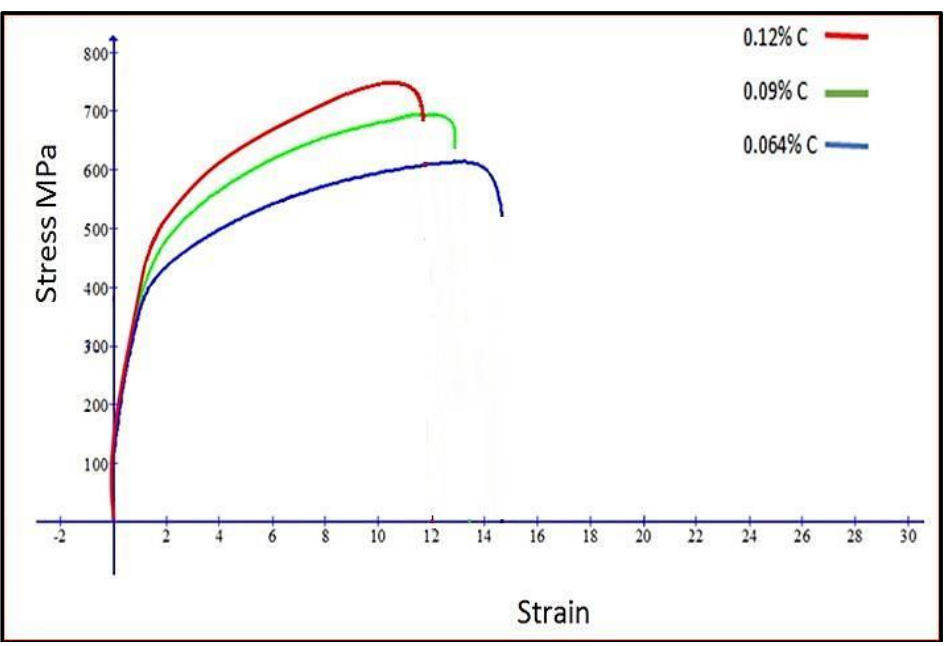

Figure 3: the stress strian curve of dual phase steel

All metals and alloys contain some dislocations that were introduced during solidification, during plastic deformation, and as a consequence of thermal stresses that result from rapid cooling dislocation densities as low as $10^{3} \mathrm{~mm}$ are typically found in carefully solidified metal crystals. For heavily deformed metals, the density of dislocations after intercritical annealing and austenite transformation to martensite reach to ${ }^{20} 10^{13} \backslash \mathrm{Cm}^{2}$.in dual phase we see continuous yielding phenomena which is no yield point appears on the curve, this is attributed to the free or un- pinned dislocation by carbon atoms. also the difference between (YS) and (UTS) is larger in DPS than those in normalized condition due to the higher strain hardening rate in DPS, these differences are presented in
Figure (4) and it is noticed that the values of (YS) and (UTS) increasing with the carbon content of the steel. During baking, process the steel will significantly, return of discontinuous yielding this phenomena can be seen in all specimens that baking process made to it the effect of baking without pre-strain on the YS and UTS of the DPS is presented in Figure (5),It is clearly showing that baking treatment reduces the UTS and YS of the tested steel. For UTS, the minimum decrease was found with $(0.12 \% \mathrm{C})$ this behavior accrue because the density of the dislocations is low if compared with the density of the dislocations caused by the pre-strainprocess, so dissolved carbon atoms are diffuse to a small number of dislocations.



Figure 4: the difference in values between YS and UTS for normalized and dual phase steel 


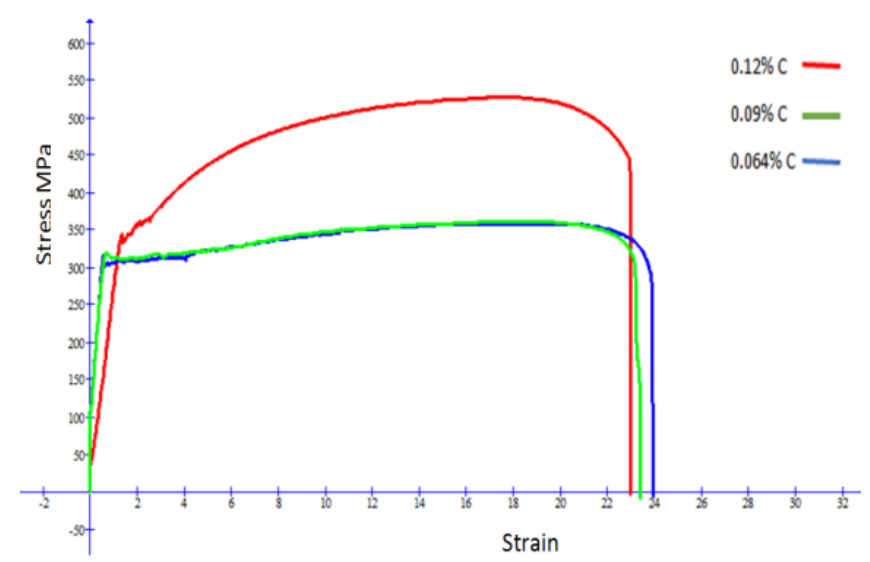

Figure 5: the effect of baking without pre-strain on the YS and UTS of the DPS

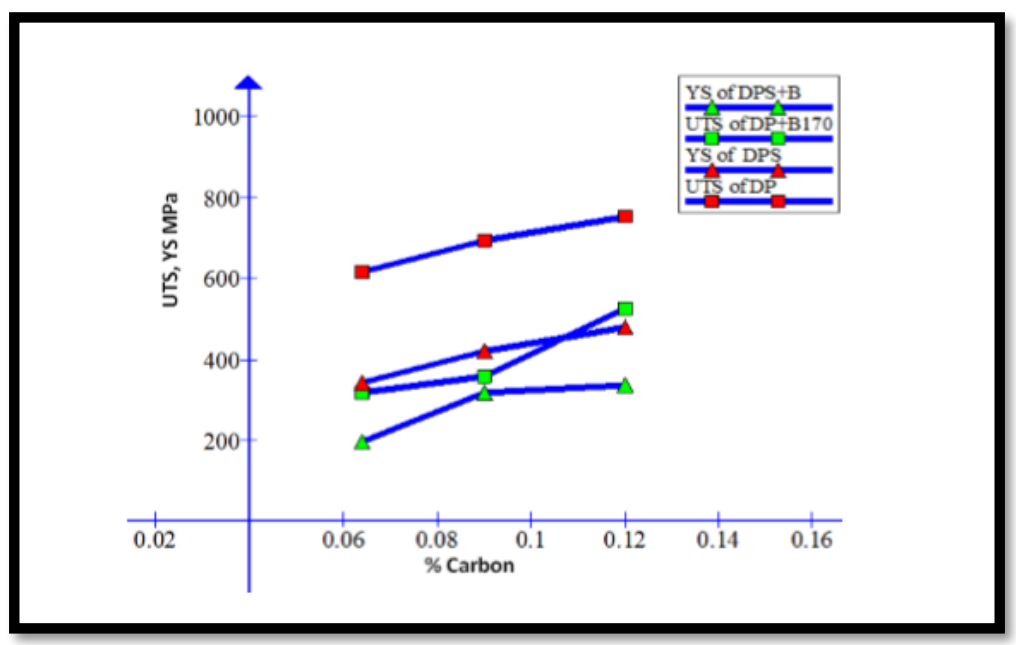

Figure 6: present the effect of baking on YS and UTS of DPS for different steel.

The tensile test specimens of (DPS) were subjected to different percentage of pre-strain, namely $(3,5,8$ and 10$)$ $\%$, the specimens then was baked at $170^{\circ} \mathrm{C}$. The tensile test results are presented in Figures 7, 8 and 9 and Table (3).

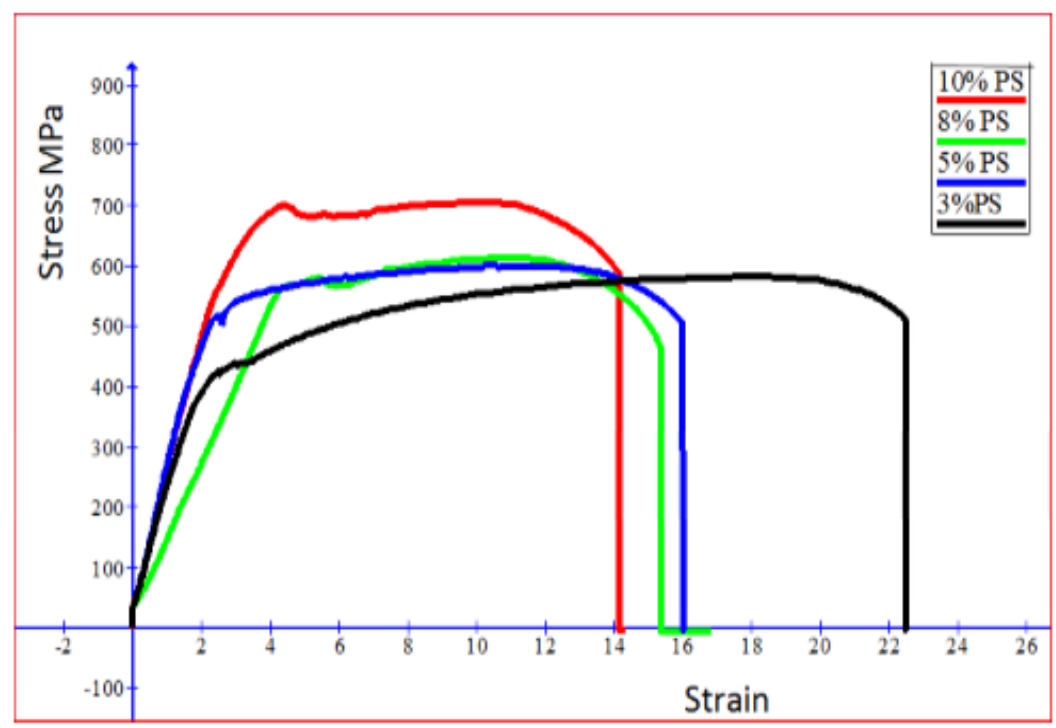

Figure 7: effect of be- strain and baking on the tensile properties of $12 \%$ dual phase steel 


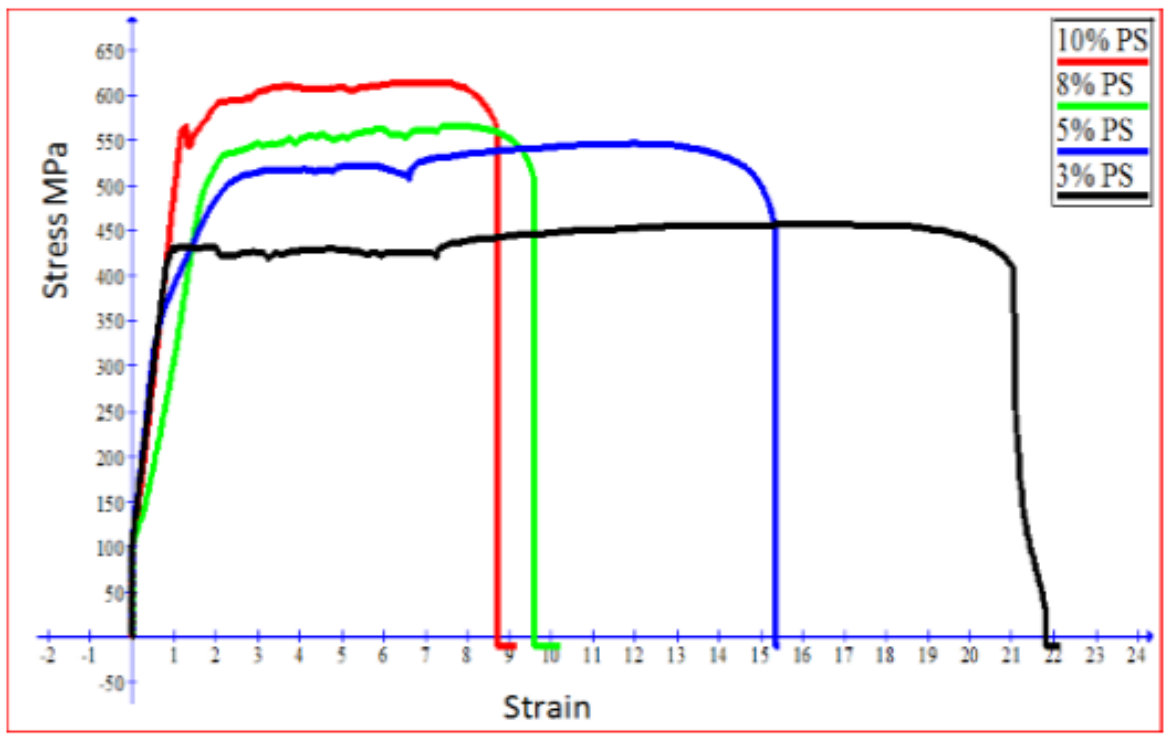

Figure 8: effect of be- strain and baking on the tensile properties of $0.096 \%$ dual phase steel

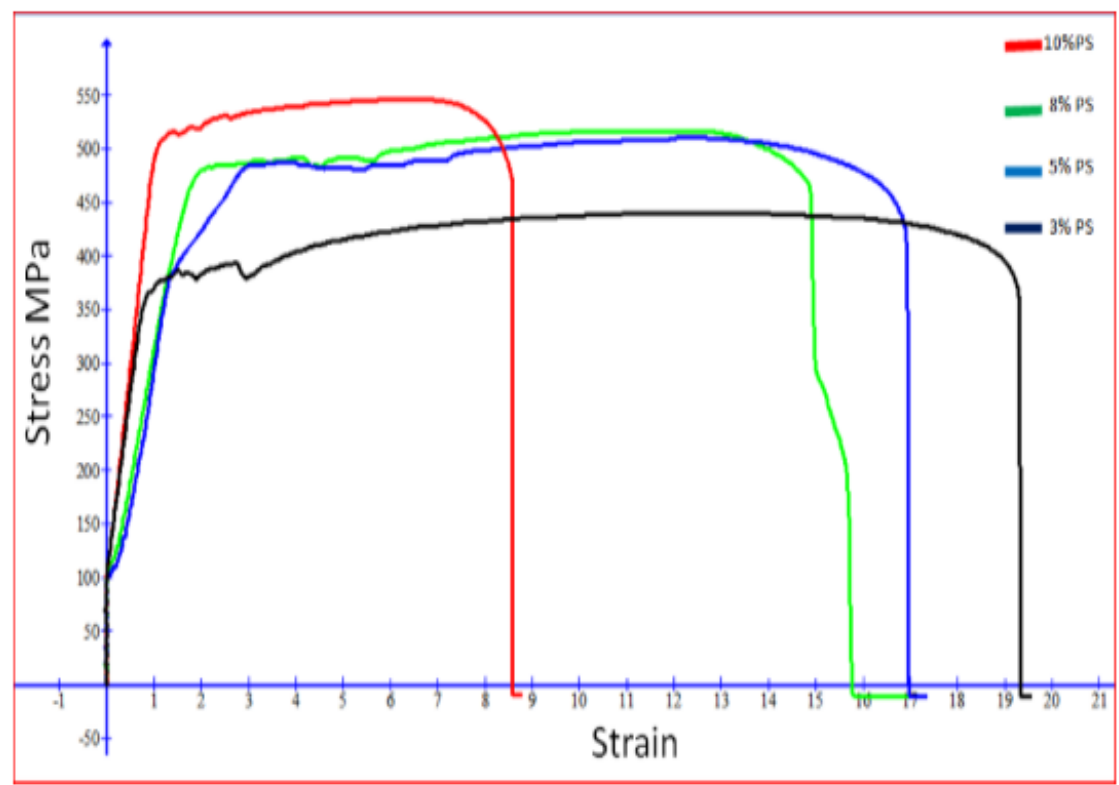

Figure 9: effect of be- strain and baking on the tensile properties of $0.09 \%$ dual phase steel

Table 3 summary of the tensile test results for pre-strained and baked specimens

\begin{tabular}{|c|c|c|c|c|c|c|c|}
\hline \multicolumn{2}{|c|}{$0.12 \mathrm{C} \%$} & \multirow{2}{*}{$\begin{array}{l}\text { DP } \\
660\end{array}$} & \multirow{2}{*}{$\begin{array}{l}\mathrm{DP}+\mathrm{B} \\
527\end{array}$} & \multirow{2}{*}{$\begin{array}{l}\mathrm{DP}+3 \% \\
+\mathrm{B} \\
580\end{array}$} & \multirow{2}{*}{$\begin{array}{l}\mathrm{DP}+5 \% \\
+\mathrm{B} \\
601\end{array}$} & \multirow{2}{*}{$\begin{array}{l}\mathrm{DP}+8 \%+\mathrm{B} \\
615\end{array}$} & \multirow{2}{*}{$\begin{array}{l}\mathrm{DP}+10 \\
\%+\mathrm{B} \\
706\end{array}$} \\
\hline B & UTS(MPa) & & & & & & \\
\hline${ }^{\circ} \mathrm{C}$ & YS (MPa) & 460 & 336 & 440 & 517 & 580 & 699 \\
\hline \multicolumn{2}{|c|}{$0.09 \mathrm{C} \%$} & $\mathrm{DP}$ & $\mathrm{DP}+\mathrm{B}$ & $\begin{array}{l}\mathrm{DP}+3 \% \\
+\mathrm{B}\end{array}$ & $\begin{array}{l}\mathrm{DP}+5 \% \\
+\mathrm{B}\end{array}$ & $\mathrm{DP}+8 \%+\mathrm{B}$ & $\begin{array}{l}\mathrm{DP}+10 \\
\%+\mathrm{B}\end{array}$ \\
\hline \multirow[t]{2}{*}{$\begin{array}{l}\mathrm{B} 170 \\
{ }^{\circ} \mathrm{C}\end{array}$} & $\begin{array}{l}\begin{array}{l}\text { UTS } \\
(\mathrm{MPa})\end{array} \\
\end{array}$ & 612 & 360 & 467 & 547 & 566 & 625 \\
\hline & YS (MPa) & 420 & 320 & 417 & 507 & 545 & 566 \\
\hline \multicolumn{2}{|c|}{$0.064 \mathrm{C} \%$} & $\mathrm{DP}$ & $\mathrm{DP}+\mathrm{B}$ & $\begin{array}{l}\mathrm{DP}+3 \% \\
+\mathrm{B}\end{array}$ & $\begin{array}{l}\mathrm{DP}+5 \% \\
+\mathrm{B}\end{array}$ & $\mathrm{DP}+8 \%+\mathrm{B}$ & $\begin{array}{l}\mathrm{DP}+10 \\
\%+\mathrm{B}\end{array}$ \\
\hline \multirow[t]{2}{*}{$\begin{array}{l}\text { B170 } \\
{ }^{\circ} \mathrm{C}\end{array}$} & $\begin{array}{l}\text { UTS } \\
(\mathrm{MPa})\end{array}$ & 600 & 319 & 440 & 510 & 517 & 546 \\
\hline & YS (MPa) & 248 & 318 & 395 & 483 & 493 & 515 \\
\hline
\end{tabular}


Bake hardening steels are characterized by a significant increase in yield strength after pre-straining, such as due to forming operations, and subsequent baking. The increase in yield stress and ultimate strength due to an interaction process of the mobile dislocations and interstitial carbon atoms in the ferrite grain interior since the carbon atoms a diffuse or immigrate to mobile dislocations that have been created through straining and pin them and form atmospheres around them. These atmospheres are known as Cottrell atmosphere. By locking the existing

mobile dislocations, the yield stress is increased and a discontinuous yielding behavior. Figures (10) and (11) are showing the effect of baking process and different percentage of pre-strain and on the UTS and YS it's seen from these figures that ultimate tensile strength and yield point strength increased after specimens subjected to baking process and pre-strain.

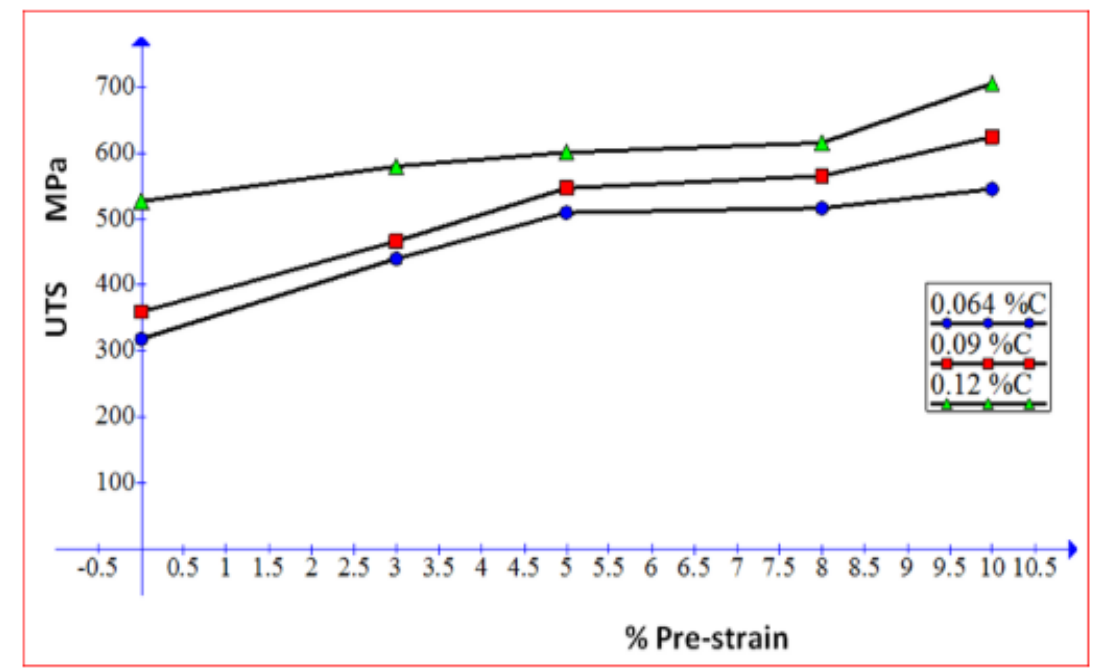

Figure 10: effect of pre-strain percentage on UTS of tested steel

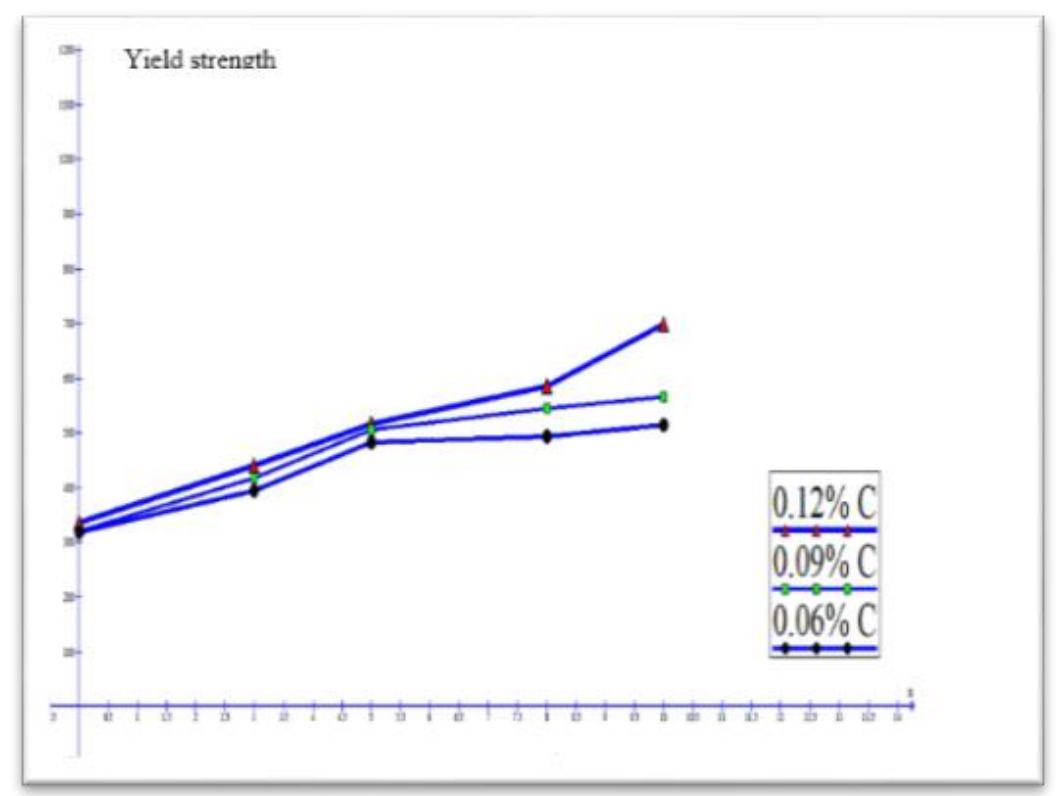

Figure 11: effect of pre-strain percentage on YS of tested steel

\subsection{Microhardness and Microstructure}

The microstructure of normalized steel and dual phase steel were presented in Figures (12) and (13). The hardness test results of normalized and (DPS) for three inspected steel are presented in Figure (14) and Table (5). The Vickers hardness number (VHN) for both conditions increases as carbon content increased, but these value of hardness of (DPS) is much higher than those of normalized condition. The increased values are $(\mathbf{1 1 1}, 94$ and 78) VHN or (76.5, 73.4 and 65$) \%$ for $(\mathbf{0 . 1 2}, \mathbf{0 . 0 9}$ and 0.06) \% carbon steel respectively. The high increase in the hardness values of DPS, is related to the microstructure formed after intercritical annealing treatment, which causes a phases transformation to (Martensite-Ferrite) instead (Pearlite-Ferrite) as in the 
normalizing case, and since Martensite is harder than Pearlite, thus DPS will be of a higher hardness than those of normalized steel. However the hardness value depends on the carbon content of the steel for the same intercritical annealing temperature, in this case as, the amount of carbon increased, the volume fraction of martensite will increase, and hence the hardness level of the steel will be higher.

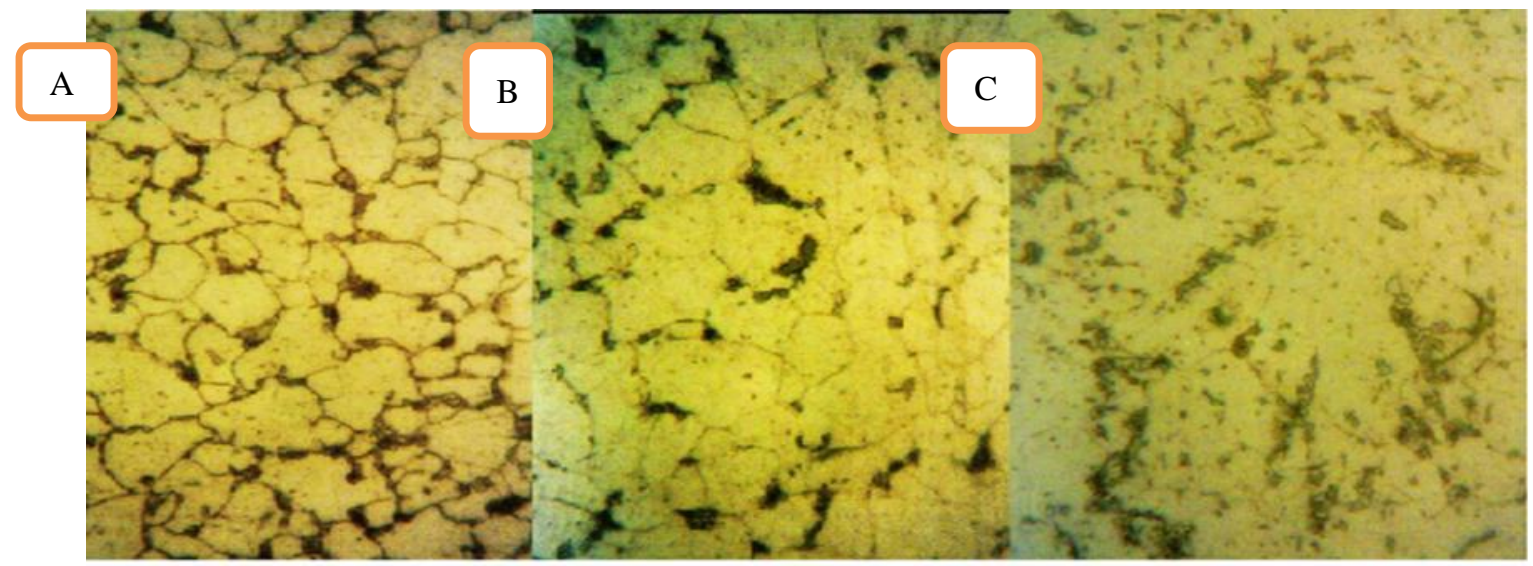

Figure 12: microphotograph of (Normalized steel), (a) 0.12, (b) 0.09 and (c) $0.064 \%$

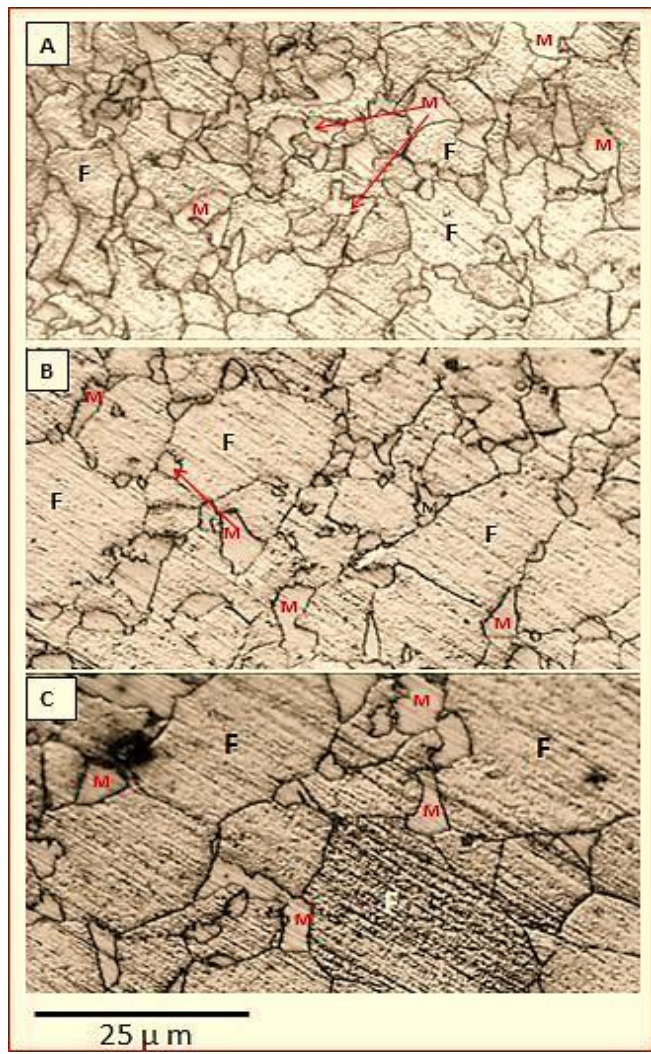

Figure 13: microphotograph of (DPS), (a) 0.12 , (b) 0.09 and (c) $0.064 \%$ Carbon steel (M-Martensite, F-Ferrite)

Table 4: Vickers hardness number (VHN) of normalized and DPS steel.

\begin{tabular}{llll}
\hline \multirow{2}{*}{ Steel } & \multicolumn{3}{c}{ Hardness VHN } \\
\cline { 2 - 4 } $\mathbf{0 . 1 2 \%} \mathbf{C}$ & 145 & DPS & Increase \\
$\mathbf{0 . 0 9 5} \% \mathbf{C}$ & 128 & 256 & $+76.55 \%$ \\
$\mathbf{0 . 0 6} \% \mathbf{C}$ & 120 & 222 & $+73.43 \%$ \\
\hline
\end{tabular}


Figure 14 (a, b, and $\mathbf{c})$ show microstructure of the DPS of carbon content $(\mathbf{0 . 1 2}, \mathbf{0 . 0 9}$ and $\mathbf{0 . 0 6 4}) \%$ respectively. The volume fraction of martensite were $(\mathbf{1 9}, 14$ and $\mathbf{1 0}) \%$ its measured by using Image $\mathrm{J}$. Also it can be noticed that the Ferrite grain size and the Martensite are increasing as the carbon content decreased, this could be related to the original grain size of the ferrite and Pearlite of the received steel.

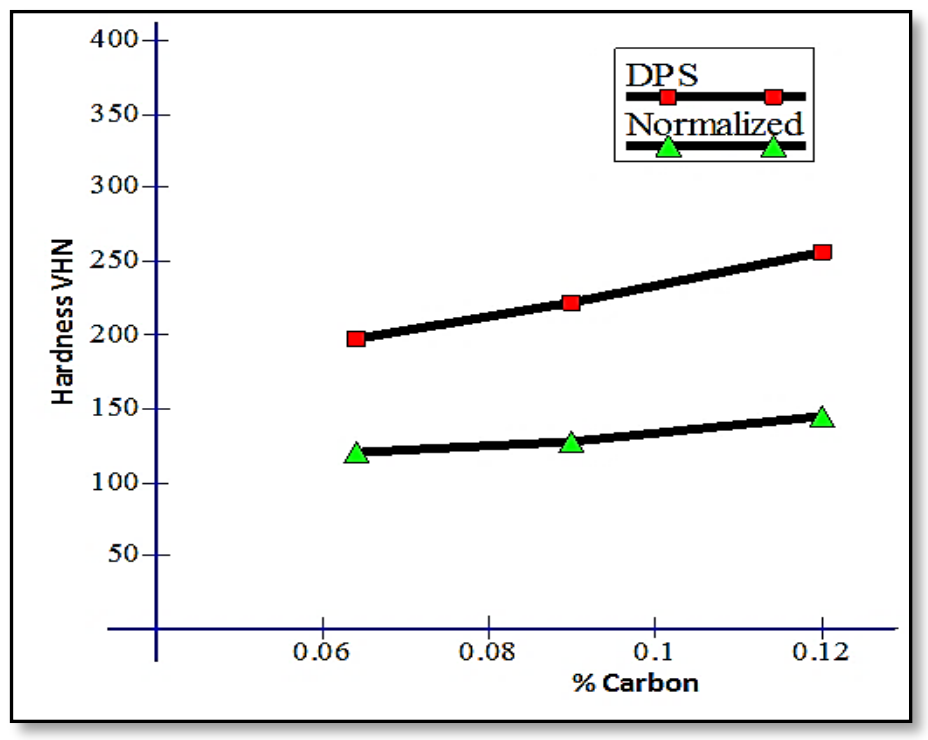

Figure 14: Effect of carbon content on the hardness of normalized and (DPS)

During intercritical annealing treatment the pearlite enrich carbon austenite in intercritical annealing is pearlite decomposition,since the pearlite fully dissolve, causes an increase volume fraction of austeniteand after quenching will transform to martensite because carbon atoms do not have time to diffuse out of the crystal structureAs a result of the quenching, the face-centered cubic austenite transforms to a highly strained body-centered tetragonal the shear deformations that result produce a large number of dislocations, which is reason of high strength and hardness of dual phase steels.

\section{Conclusions}

The main conclusions of the present work can summarized as follows:-

1- Intercritical annealing process transform low carbon steel in to dual phase steel (DPS) contains ferrite and martensite.

2- Volume fraction of martensite increasing depend on carbon content during intercritical annealing temperature, hardness also depend on carbon content.

3- Tensile test profiles of the (DPS) shows continuous yielding for all investigated steel

4- The difference between yield strength (YS) and ultimate tensile strength (UTS) are higher in (DPS) than in normalized steel.
5- In the baking process we observe the return of the yield point whether the baking process with or without the pre-strain.

6- The value of yield point and ultimate tensile strength increased with pre-strain percentage increasing followedby baking process

\section{References}

[1]. D. Westerbaan, W. Xua, S. S. Nayak, DL. Chen, F. Goodwin, Y. zhou, "Tensile and fatigue properties of fiber laser welded high strength low alloy and DP980 dual-phase steel joints" Materials and Design 43 (2013) 373-3.

[2]. Adeolu Adesoji, ADEDIRAN, Muhammed Olalekan Hakeem AMUDA, Sunday ARIBO,"Mechanical properties of dual phase steel quenched in bitumenmedium "Leonardo Electronic Journal of Practices and TechnologiesISSN 1583-1078Issue 26, January-June 2015, p. 1-16.

[3]. H. Ghassemi-Armaki, R. Maaß., S.P. Bhat, S. Sriram, J. R. Greer, K. S. Kumar "Deformation response of ferrite and martensite in a dual-phase steel". Acta Materialia 62 (2014) 197-211.

[4]. Irina Pushkareva, Sébastien Allain, Colin Scott, Abdelkrim Redjaïmia, Antoine Moulin "Relationship between Microstructure, Mechanical Properties and Damage Mechanisms in High 
Martensite Fraction Dual Phase Steels" ISIJ International Vol. 55 No. 10, (2015) p. 2237-2246.

[5]. Xiaojun Xu., Sybrand van der Zwaag, WeiXu "The effect of martensite volume fraction on the scratch and abrasion resistance of a ferrite-martensite dual phase steel". Wear 348-349 (2016) 80-88.

[6]. L. Schemmann, D. Raabe, F. Friedel, "Alloying effects on microstructure formation of dual phase steels" Acta Materialia 95 (2015) 386-398.S. Zaefferer

[7]. Ersoy Erișir, Oğuz Gürkan Bilir. "A Study of Microstructure And Phase Transformation of Medium Carbon Dual Phase Steels"Metal15. - 17. 5., Brno, Czech Republic, EU (2015) pp 1417-1423.

[8]. Majid Pouranvari, "Tensile Strength And Ductility of Ferrite-Martensitedual Phase Steels" Association of Metallurgical Engineers of Serbia MJoM Vol. 16 (3) (2010) p. 187-194.

[9]. Z P .Xiong, A G. Kostryzhev, N E. Stanford, E V. P ereloma "Microstructures and mechanical properties of dual phase steel produced by laboratory simulated strip casting "University of Wollongong Research Online Materials and Design, (2015) 537-549.

[10]. Süleyman Gündüz "Bake-Hardening Response of High Martensite Dual- Phase Steel with Different Morphologies and Volume Fractions "Acta Metall. Sin. (Engl. Lett.), 27(2), (2014) 279-289.

[11]. Hemantha kumaryeddu "Martensitic Transformations in Steels - A 3D Phase-field Study" PhD Thesis Stockholm, Sweden, 2012.

[12]. Sourav Das "Bake Hardening In Low And Medium Carbon Steels " PhD Thesis submitted to Indian Institute of Technology, Kharagpur for the award of the degree Doctor of Philosophy May, 2012.

[13]. Sourav Das "BAKE HARDENING IN LOW AND MEDIUM CARBONSTEELS " PhD Thesis submitted to Indian Institute of Technology, Kharagpur for the award of the degree of Doctor of Philosophy May 2012 .

[14]. K. A. Bello, S.B. Hassan, M. Abdulwahab, U. Shehu, L. E. Umoru, A. Oyetunji, I.Y. Suleiman, "Effect of Ferrite-Martensite Microstructural Evolution on Hardness and Impact Toughness Behaviour of High Martensite Dual Phase Steel". Australian Journal of Basic and Applied Sciences, 1(4): (2007) 407-414.

[15]. S. K. AKAY, M. YAZICI, A. AVINC "The Effect of Heat Treatments on Physical Properties of A Low carbon steel" PROCEEDINGS oF THE ROMANIAN ACADEMY, Series A, Vol. 10, No. 1. (2009).

[16]. M. R. AKBARPOUR F. NEMATZADEH, S. E. HASEMI AMIRI, H. REZAII "Effect of long duration intercritical heat treatment Effect of long duration intercritical heat treatmenton the mechanical properties of AISI 4340 steel "Materials SciencePoland, Vol. 28, No. 2. (2010).
[17]. Martin Gaško, Gejza Rosenberg (2011) "Correlation Between Hardness Andtensile Properties In Ultra-High Strengthdual Phase Steels - Short Communication" Materials Engineering Materiálovéinžinierstvo 18 (2011) 155-159.

[18]. L. Durrenberger, X. Lemoine, A. Molinari "Effects of pre-strain and bake-hardening on the crash properties of a top-hat section" Journal of Materials Processing Tech. P. 211, V01. 12. (2011).

[19]. Emil EVIN "Desing Of Dual Phase High Strength Steel Sheets For Autobody "Technical Univerzity of Košice, Kosice, Slovak Republic, EU ‘.5 .17 - .15 Brno, Czech Republic. (2013). 